\title{
A RELAÇÃO FAMÍLIA-ESCOLA E SUA CONTRIBUIÇÃO NO RENDIMENTO ESCOLAR DE CRIANÇAS COM NECESSIDADES EDUCATIVAS ESPECIAIS QUE POSSUEM DIFICULDADES DE APRENDIZAGEM
}

\section{ARTIGO ORIGINAL}

SANTOS, Lúcia Maria Matos Silva ${ }^{1}$

SANTOS, Lúcia Maria Matos Silva. A relação família-escola e sua contribuição no rendimento escolar de crianças com necessidades educativas especiais que possuem dificuldades de aprendizagem. Revista Científica Multidisciplinar Núcleo do Conhecimento. Ano. 06, Ed. 09, Vol. 07, pp. 78-94. Setembro 2021. ISSN: 2448-0959, Link de acesso:

https://www.nucleodoconhecimento.com.br/educacao/familia-escola, DOI: 10.32749/nucleodoconhecimento.com.br/educacao/familia-escola

\section{RESUMO}

O desenvolvimento do presente artigo tem como temática a educação especial, assunto este que vem ganhando espaço no cenário e nos debates educacionais de todo o país. Tem como questão norteadora, como a relação família-escola contribui no rendimento escolar de crianças com necessidades educativas especiais que possuem dificuldades de aprendizagem? Sendo assim, o objetivo deste artigo, se baseia na verificação de como a relação da família com a escola contribui no rendimento escolar do aluno com necessidades educativas especiais (NEE) que possui dificuldades de aprendizagem, apresentaremos, também, de acordo com a literatura, algumas das possíveis origens das dificuldades destas crianças. Tendo em vista uma melhor compreensão desta temática, o texto resulta de um estudo

\footnotetext{
${ }^{1}$ Doutorado em Ciências da Educação pela Universidad San Carlos - USC. Mestrado em Ciências da Educação pela Universidad San Carlos-USC. Graduada em Educação Artística, com habilitação em Desenho Universidade Católica de Salvador - UCSAL. Também graduada em Matemática, em licenciatura plena pelo programa Especial de Formação Pedagógica e graduada em Pedagogia - Universidade Cruzeiro do Sul; Especialização em Psicopedagogia - Universidade Salgado Oliveira.
}

RC: 98080

Disponível em: https://www.nucleodoconhecimento.com.br/educacao/familia-escola 
bibliográfico que teve como centralidade analisar, compreender e contrastar a proposta dos alunos com necessidades educativas especiais, da problemática da relação família e escola, considerando crianças com NEE. Desta forma, os resultados revelaram a importância do papel do professor no crescimento dos seus alunos/filhos para os pais, onde foi possível compreender a importância da relação entre pais e escola para o desenvolvimento e melhor rendimento escolar de crianças com NEE que possuem dificuldade de aprendizagem, e como isso fortalece seu processo de integração e aprendizagem.

Palavras-chave: Necessidades Educativas Especiais, Família, Escola, Educação, Cooperação.

\section{INTRODUÇÃO}

O presente artigo teve como inquietação analisar, numa abordagem descritiva, a influência da relação família-escola no rendimento escolar de alunos com necessidades especiais na educação que possuem dificuldades de aprendizagem e a importância da relação entre a escola e a família do aluno que possui necessidades educativas especiais (NEE) como forma de contribuir no seu rendimento escolar. Apresenta uma reflexão contextualizada ao nível do ensino regular, ou seja, fundamental II, a fim de compreender a importância que a família em conjunto com a escola, assumem no processo educativo destes jovens.

Para tanto, o estudo teve como objetivo geral verificar como a relação da famíliaescola contribui no rendimento escolar do aluno com necessidades educativas especiais (NEE) que possui dificuldades de aprendizagem. Os objetivos específicos foram: Analisar algumas teorias relacionadas ao desenvolvimento cognitivo, a fim de compreender como a relação família-escola contribui no desenvolvimento do aluno; verificar algumas possíveis origens das dificuldades de aprendizagem, de acordo com estudiosos da área; verificar, através da bibliografia, como a relação famíliaescola contribui no desenvolvimento de alunos com NEE. 
Para o alcance destes objetivos foi necessário fazer o questionamento: como a relação família-escola contribui no rendimento escolar de crianças com necessidades educativas especiais que possuem dificuldades de aprendizagem? Tendo em vista que o fortalecimento da participação parental no desenvolvimento educativo, junto à instituição de ensino, pode-se estabelecer e manter uma relação entre escola e pais de crianças com NEE, de forma a promover uma mudança positiva de atitudes e práticas em benefícios destes alunos.

Portanto, este estudo justifica-se através de uma inquietação acerca da Educação Especial no âmbito de proporcionar uma ação entre políticas públicas educacionais e sociais, contribuindo, desse modo, tanto para a diminuição das desigualdades educacionais, quanto pela valorização da diversidade cultural brasileira.

Compreende-se que a relação família-escola é basilar para um bom rendimento escolar e para o desenvolvimento de crianças com NEE diante do mundo, conhecendo os principais fatores que interferem na relação entre família $x$ escola.

\section{TEORIAS SOBRE DESENVOLVIMENTO COGNITIVO}

Para melhor contextualizar o ensino-aprendizagem para alunos com NEE, faz-se necessário o entendimento sobre o que leciona o psicólogo russo, Lev Vygotsky (1896-1934), sobre teorias relacionadas ao desenvolvimento cognitivo e a relação entre o entendimento e a linguagem. Vygotsky (2000) assinala a existência de quatro estágios durante a construção das operações mentais que abrangem o uso dos signos:

- O primeiro estágio, que recebeu nome de "natural ou primitivo", corresponde à fala pré-intelectual (balbucio, choro, riso) e a ideia pré-verbal que se caracteriza por manifestações intelectuais rudimentares, relacionadas ao manejo de instrumentos;

- O segundo estágio compreende o "das experiências psicológicas ingênuas", período marcado pelo uso correto das formas e estruturas gramaticais, apesar 
da criança ainda não ter compreendido suas respectivas representações lógicas;

- No terceiro estágio, "dos signos anteriores", o pensamento atua com operações externas. Tais operações são apropriadas pela criança para resolver problemas internos. Assim, é definido pelo período da linguagem egocêntrica;

- E o quarto estágio, que é denominado de "crescimento interior" e se caracteriza pela interiorização das operações externas, é o estágio da fala interior ou silenciosa.

Para Vygotsky (2000), essas etapas de desenvolvimento cognitivo não possuem caráter universal, em razão da existência de uma grande diversidade nas condições histórico-sociais em que as crianças vivem, tornando o social evidente no desenvolvimento do pensamento. De acordo com o autor, o desenvolvimento do pensamento determina-se pelos instrumentos linguísticos e pela experiência sociocultural da criança, o que inclui o convívio familiar, a forma como essa relação se apresenta e como reflete no desenvolvimento educativo do aluno (VYGOTSKY, 2000).

De acordo com Alves (2007), é preciso sonhar, mas sonhar os sonhos possíveis de serem realizados. Em complemento, Paulo Freire (1982) considera que os sonhos podem se tornar realidade quando há o empenho em solucionar problema que se apareçam, que eles podem modificar o imaginário social, passado por várias décadas, quando se sonha o sonho possível e transforma a inclusão de crianças com NEE, em sucesso escolar. Desta forma, permite-se que a família, escola e professores possam juntos ter um ensino de qualidade.

Compreende-se que a educação das pessoas com necessidades educacionais especiais sempre esteve permeada de dúvidas e incertezas por parte de muitos educadores que questionam a maneira como eles podem aprender e qual melhor forma de ensinar. Entretanto, é notório o despreparo de algumas famílias em auxiliar seus filhos com NEE no sentido educativo, tendo em vista que nem sempre a escola possui esse preparo. Entretanto para muitos educadores tem sido um desafio diário 
promover a inclusão de alunos com NEE em classes regulares juntamente com outros alunos ditos "normais" (IOSIF, 2007).

O conceito de necessidades especiais surgiu no sentido de evitar os efeitos negativos de expressões utilizadas no contexto educacional-deficientes, excepcionais, subnormais, superdotados, incapacitados entre outros (BRASIL, 2006).

O conceito de necessidades especiais é parte inerente dos princípios e valores da educação inclusiva. Pois, uma escola inclusiva, é uma instituição educacional que oferece todos os recursos disponíveis para atender as necessidades educacionais de todos os alunos que frequentam, colocando a seu dispor os apoios apropriados e os serviços necessários que Ihes permitam ter êxito educativo (BRASIL, 2006).

Tomando como base a lei de Diretrizes e Bases da Educação (LDB) - Lei no 9394/96, no art. 58, a educação especial deve ser oferecida preferencialmente na rede regular de ensino, deste modo percebe-se uma quantidade maior de educandos com necessidades educacionais especiais inseridos na rede regular de ensino, e muitos professores estão sendo preparados para trabalhar com esses alunos de acordo com a especificidade de cada um, mas muitos ainda se sentem incapazes e relutam contra este desafio (BRASIL, 1996).

A educação inclusiva prioriza o atendimento das pessoas com deficiência em classes comuns, sempre que possível, pois a depender do tipo de deficiência a escola necessita fazer toda uma adaptação para depois acolher esses alunos, oferecendo condições físicas, e materiais pedagógicos para desenvolverem suas potencialidades (BRASIL, 1996).

Tendo em vista as afirmações acima, compreende-se que a escola regular tem procurado atender aos alunos com NEE adaptando materiais pedagógicos e espaços físicos de acordo com a necessidade do educando, deste modo, a inclusão vem sendo aos poucos tratada de forma mais natural, sendo que os alunos ditos "normais" têm se mostrado dispostos a ajudar o colega com necessidades 
educacional especial, e isto faz a diferença, promove a integração e cumpre um dos direitos fundamentais de todo ser humano: promover a educação.

Foi pensando nas questões que envolvem alunos NEE entre algumas famílias e professores da rede municipal de Dias D' Ávila que nasceu o interesse por essa temática, devido à importância da participação familiar em conjunto com a escola a fim de prevenir, compreender as dificuldades de aprendizagem de alunos com NEE e aprimorar suas habilidades. Desta forma, a educação visa o desenvolvimento integral do ser humano, tendo em vista à formação do caráter da personalidade social e habilidades pois, a educação voltada aos jovens e crianças com NEE reveste-se de importância social, permitindo a sua inserção em uma sociedade que muitas vezes não está preparada para atender às suas necessidades especiais. Entretanto, ainda assim existe a particularidade de permitir a frequência das crianças nas salas de aula pública junto a outras não "deficientes" ou de permitir que o adulto se torne competitivo no mercado de trabalho, observando que o papel do professor no processo de ensino aprendizagem é introduzir no ambiente dos alunos elementos capazes de provocar uma situação de conflito, que poderá levá-los a aprender, independente do modo que agirão a partir desse conflito (LEONARDO, et al. 2009).

Uma vez que a ação pedagógica deve caracterizar-se por atividades didáticas que sirvam de apoio para os alunos se apoderarem do saber e não apenas adquirirem, pois, receber não implica necessariamente em aprender (LEONARDO, et al. 2009).

Segundo estudos de Piaget, o aprendizado está ligado ao desenvolvimento cognitivo do aluno, pois quando o conhecimento se transforma em ação, acontece à aprendizagem, cujo objetivo é a autonomia do sujeito (DÍAZ, 2011).

É possível compreender, portanto, que o professor voltado à educação especial ocupa uma posição relevante na formação do aluno, como profissional e cidadão, pois coloca à disposição do aluno com NEE uma série de experiências pertinentes ao trabalho e à vida, essas experiências estimulam o aluno na busca de conhecimento teórico e prático, possibilitando-Ihe aprender. 
Quando Miranda (1999, p. 44), diz que a família e a escola devem encontrar formas criativas e organizadoras de convencer a comunidade a participar, através de parcerias, da manutenção para a integração e a inclusão, pois quando há a conscientização das pessoas envolvidas, o futuro toma seu rumo, ou seja, quando os alunos estão bem integrados e incluídos nas salas de aula, provavelmente haverá a parceria entre professor, família e escola. Mas quando tudo isso não acontece, os alunos com NEE ao invés de estarem integrados e incluídos, estejam segregados ou excluídos; a falta de preparação de professores de classe comum pode trazer prejuízos aos alunos especiais; nem todos os alunos portadores de necessidades especiais são aptos para integração e inclusão, alguns precisam de atendimento individual e especializado; a atenção dos governantes para com a educação é escassa; a participação da família, que é de grande relevância, tem ficado aquém do necessário (MIRANDA, 1999).

A princípio da normalização, Sassaki (1997, p. 31), afirma que como pressuposto básico a ideia de que toda pessoa com necessidades especiais, especialmente aquela portadora de deficiência mental, tem direito de conhecer um estilo ou modelo de vida que seria comum ou normal à sua cultura pessoal. O conceito inicial foi, então, a de normalizar, mas isto foi confundido com a consciência de "tornar normais às pessoas com necessidades especiais".

Partindo do princípio de que os seres humanos se desenvolvem pelas relações que estabelecem com o seu meio, Philippe Perrenoud (2001), vê as capacidades não como um caminho, mas como uma consequência adaptativa do homem às suas condições de vida. Assim, cada pessoa, de maneira diferente, desenvolveria capacidades voltadas para a resolução de problemas relativos à superação de uma circunstância, como, por exemplo, saber orientar-se no trajeto de volta para casa a partir de um ponto de referência, o que mobiliza capacidades de reconhecimento pedagógicas; saber construir ferramentas, o que estimula competências, ou seja, os alunos com NEE por si só precisam caminhar iguais aos ditos "normais", numa forma de unir família, professor e escola de maneira que ambos façam uma conexão, ou seja, parceria aluno, família e escola. 
A criança no momento do seu nascimento é um ser puramente biológico, pronto a receber qualquer tipo de influência. É no grupo que nasce (a família) que ocorre o processo inicial de integração social. $O$ processo de socialização obriga que a criança adapte os seus comportamentos, biologicamente determinado, às práticas culturais do grupo social a que pertence, os valores, as atitudes, os conhecimentos adquiridos no seio da família visam a tornar o indivíduo apto a assumir de forma adequada a diferentes situações (GALLO; ALENCAR, 2012).

A escola é uma instituição que transmite os conhecimentos científicos e técnicos que irão permitir ao indivíduo exercer um papel no aparelho produtivo, contudo, a escola tem outra função essencial: vincular as normas sociais, a noções de ética básica e de ideais da sociedade, será todo esse conjunto de aquisições que irá facilitar a inserção social do indivíduo. Desta forma, família precisará do apoio e da colaboração, fundamental, da escola nesse processo de integração e socialização do indivíduo. Esse apoio será mais exigido, quando se tratar de uma criança considerada "diferente" (GALLO; ALENCAR, 2012).

Diante do exposto, pode-se afirmar que a família e a escola têm papel distinto uma da outra, mas, no entanto, papéis esses que se completam no processo de desenvolvimento e integração do indivíduo ao longo do seu percurso. Compreendese também que família e escola tornam-se os dois motores de aprendizagem e desenvolvimento para a criança, com papéis e competência específicas e complementares, a escola e a família estão frequentemente separadas, ou seja, não estão partilhando juntas, uma vez que a família é a principal responsável pelas ações do seu filho com NEE, é ela que the oferece a primeira formação, na integração e inclusão escolar, o aluno, com a orientação dos profissionais e da família, poderá adquirir competência profissional e pessoal.

Quando a relação entre a família e a escola é, de modo geral, desejável, torna-se imprescindível, quando se resolve a precária das Necessidades Educativas Especiais, no entanto, a relação entre pais e professores tem, seguramente, de sofrer alterações aos mais variados níveis (mentalidades, atitudes, estratégias, 
práticas, entradas e saídas) constituindo-se, enquanto processo gerado pela mudança e gerador dela, num verdadeiro desafio.

\section{POSSÍVEIS ORIGENS DAS DIFICULDADES DE APRENDIZAGEM DE ALUNOS COM NECESSIDADES ESPECIAIS NA EDUCAÇÃO}

As dificuldades de aprendizagem têm no pensador e sociólogo francês Edgar Morin (2011) uma profunda reflexão, que pode ser verificada na elaboração da sua obra sobre a educação.

No que diz respeito a alunos com necessidades especiais na educação, Morin (2011) cria um debate que está inserido na sua teoria da complexidade, que trata da relação entre sujeito e objeto, ordem e desordem, em que reconhece em si mesma "uma zona obscura, irracional e incerta, abrindo-se ao acaso, à álea, à desordem, ao anômico e ao estrutural" (ESTRADA, 2009, p.85).

Nesse sentido, o segmento da educação demanda por uma reflexão mais acentuada sobre a interação entre local e global, quando trata da inserção do aluno em salas regulares. De acordo com Ballone (2004) as dificuldades de aprendizagem devem ser tratadas como desafios que fazem parte do processo de ensino e aprendizagem, e não como problemas sem solução. Além disso, salienta a importância em se identificar essas necessidades ainda na pré-escola, a fim de preveni-las.

Crianças com NEE dependem de uma rede de apoio para conseguirem não só o sucesso escolar, mas também a inclusão. São diversos os obstáculos encontrados no processo educativo dessas crianças, tendo em vista que requer a participação de todos. Ao educador cabe repensar a diferença, as singularidades tendo em vista que cada indivíduo é único e possui características, interesses, capacidades e necessidades de aprendizagem que lhe são singulares (BRANDÃO; FERREIRA, 2013).

É necessário ter atenção na compreensão das diferenças, das características e ferramentas motivadoras para cada aluno de forma diferenciada. Atentar aos 
detalhes e fatores alheios ao ambiente escolar, como o ambiente familiar, deve ser prioridade para possibilitar um plano estratégico que contribua no ensino aprendizagem, através de recursos e métodos educativos capazes de promover o desenvolvimento global dessas crianças (AINSCOW, 1999).

Edgar Morin (2011) compreende a classe escolar como uma instituição complicada, que abrange uma diversidade de impulsos, estratos socioeconômicos, emoções e culturas, consequentemente, ele a vê como um lugar cheio de heterogeneidade. Desta forma, ele acredita ser este o espaço ideal para se dar início a uma mudança dos paradigmas, da maneira tradicional de se pensar o ambiente escolar, em que 0 ensino-aprendizado é efetivado de forma engessada, sem observar as particularidades e a pluralidade dos alunos em sala de aula. É necessário que este contexto tenha um intenso sentido para os alunos e para os professores.

Por conseguinte, a classe escolar necessita conhecer os aspectos da heterogeneidade, quando trata de alunos que precisam de uma preparação mais condizente para o seu acolhimento. Utilizando o rumo indicado por Morin (2011), ou seja, o da visão que se extrai do âmbito estreitado da disciplina, que entende o contexto e adquire o poder de encontrar a ligação com a existência, pode-se fazer uma analogia com essa visão voltada para o âmbito do contexto da aprendizagem dos alunos considerados normais e os portadores de necessidades especiais.

Em concordância com o autor supracitado, verifica-se que é preciso romper com a fragmentação da informação em campos restritos, no íntimo dos quais se privilegiam certos teores, e eliminar a estrutura hierárquica vigente entre as disciplinas e as formas de transmissão do conhecimento. Restaurar estas tradições requer um esforço complexo, visto que esta intelectualidade foi criada ao longo de inúmeras décadas (MORIN, 2011).

As situações de baixo rendimento escolar em que as crianças se encontram as levam a não acreditar nelas, a desenvolver baixa autoestima, a acreditar que não são capazes e por isso não são aceitas no ambiente em que estão inseridas, seja 
escolar ou familiar. Proporcionar um ambiente socioafetivo permite a elevação da autoestima dessas crianças (ELIAS, 2003).

Diante disto, é preciso identificar a necessidade criar um ambiente escolar de inclusão, em que as práticas pedagógicas se relacionem com as singularidades de cada aluno, a fim de melhorar as rotinas educativas e contribuir para um efetivo aprendizado dos alunos (MORATO, 2003).

De acordo com estudo realizado por Mazer et al. (2009), é muito comum encontrar crianças com dificuldades de aprendizado no ambiente escolar e, nelas, percebe-se diversos fatores de risco que impactam ainda mais, como pobreza, conflitos familiares, violência, maus tratos familiares, dentre outros. Além disso, os autores identificaram que a dificuldade no aprendizado também manifesta prejuízos emocionais e comportamentais nos estudantes.

Desta forma, compreende-se que o papel do professor, enquanto facilitador da aprendizagem é também de estar atento às diversas manifestações de dificuldades apresentadas pelos alunos. A família enquanto responsável pela aprendizagem da criança deve entender seu papel enquanto exemplo aos filhos, como aqueles que primeiro transmitem atitudes que beneficiam o aprendizado, cujas ações são vistas e aprendidas por eles, devem compreender a importância e o quanto isto irá determinar a forma que suas crianças aprendem (FERNANDES, 2001).

Do ponto de vista de Morin (2011), é necessário atentar para alguns fatores pertinentes à educação de alunos com NEE, fundamentais na construção de um processo educativo bem-sucedido. $\mathrm{O}$ autor indica a necessidade de se valorizar o erro enquanto instrumento de aprendizagem, pois não ter intimidade com algo sem primeiro cair nos desacertos ou nas ilusões é comum e, portanto, deve ser aceito e compreendido como parte do processo de aprendizagem.

Pais e educadores devem contribuir também para o desenvolvimento do autoconhecimento destes alunos, de forma que a educação permita o universal, as variadas dimensões do ser humano e da sociedade, em que se fortaleça a 
diversidade dentro do próprio indivíduo, sua complexidade e o entendimento de onde reside os seus medos e necessidades (MORIN, 2011).

Desta forma, compreende-se que a disseminação do conhecimento precisa ir de encontro com sua fragmentação. É preciso compreender que o aluno com NEE é um ser multidimensional, que tem urgência em enfrentar suas incertezas e dúvidas, necessitando de uma participação ativa entre a escola e seus responsáveis para que consiga melhor desenvolver suas habilidades educativas no espaço escolar.

\section{A RELAÇÃO FAMÍLIA- ESCOLA E SUA CONTRIBUIÇÃO NO RENDIMENTO ESCOLAR DE CRIANÇAS COM NEE}

Toda a sociedade tem ao longo dos tempos, recorrido a práticas reguladoras face ao "diferente", e criança com Necessidades Educativas Especiais (NEE) não foi exceção (LOUREIRO, 2013). Nos dias de hoje, diferentemente de outra que a família "escondia "as crianças ditas "diferentes", um número crescente de crianças (LOUREIRO, 2013).

No Brasil, o atendimento às pessoas com NEE teve início no período do Império em foram fundados o Instituto dos Meninos Cegos em 1854 e o Instituto dos Surdos Mudos em 1857 (atualmente Instituto Nacional da Educação dos Surdos - INES) (BRASIL, 2010).

No início do século XX é fundado o Instituto Pestalozzi (1926), instituição especializada no atendimento às pessoas com deficiência mental; em 1954, é fundada a primeira Associação de Pais e Amigos dos Excepcionais - APAE, e, em 1945, é criado o primeiro atendimento educacional especializado às pessoas com superdotação na Sociedade Pestalozzi, por Helena Antipoff. (BRASIL, 2010, p. 11).

Após a percepção de comunidade, família, escola e Governo a respeito de proporcionar às crianças com NEE a possibilidade de se desenvolverem em ambiente escolar, inicia na sociedade um processo de sensibilização e discussão sobre a educação para jovens e crianças com NEE (MIRANDA, 2003). 
Com a inserção dos filhos na escola, a família é posta em prova no exterior, quer em termos das competências que a criança manifesta para a aprendizagem, quer em termos das competências do relacionamento com os outros (OLIVEIRA, 2018).

A criança transporta para a escola a aprendizagem e experiências significativas que faz na família e noutros sistema de vida, mas confronta-se aí com outras formas de comunicação e expressão de afetos, com outros valores e regras. Este contato com novos modos de vida e com novos saberes implica, se o desenvolvimento da criança está a processar saudavelmente um reforço da sua competência e segurança, implica que à medida que ele cresce os pais deixam de serem os únicos mentores, o professor, os colegas passam também a ser um exemplo (LOUREIRO, 2013).

O envolvimento parental conduz ao sucesso, as crianças cujos pais mantêm contatos com a escola, têm pontuação mais elevadas que as crianças com aptidão e meio familiar semelhantes, mas privadas de envolvimento parental (MIRANDA, 2003).

As escolas que apresentam altas taxas de reprovação melhoram imensamente quando os pais são solicitados a ajudar, pois, a integração entre essas duas instituições traduz o compartilhamento e a continuidade da tarefa de preparar e encaminhar os sujeitos para a vida nos seus mais variados aspectos (HENDERSON cit. DAVIS, 1989, p. 38).

A viabilidade da relação entre a família e a escola depende de colaboração, confiança e respeito entre as partes, para que o alcance dos objetivos educativos seja produtivo e significativo, tento em vista que a participação dos pais na educação dos seus filhos é um direito e um dever (CARDOSO, 2011).

De acordo com Cardoso (2011):

A importância do papel da família na educação das crianças e jovens com NEE, tal como das outras crianças sem problemas, é sem dúvida fundamental e indiscutível. É pois essencial a participação dos pais em todo o processo educativo, através de uma estreita colaboração entre escola/família. Os pais são participantes indispensáveis na medida em que contribuem com o

RC: 98080

Disponível em: https://www.nucleodoconhecimento.com.br/educacao/familia-escola 
conhecimento específico que têm do filho e da sua situação familiar e manifestam as suas preocupações e expectativas relativamente ao seu futuro (p.29).

De acordo com Davis (1994, p.82), referenciando Bourdieu, os pais que mais facilmente se envolvem de modo positivo na escola, são os que culturalmente mais se identificam com os valores que são vinculados e legitimados pela escola, a escola e os professores adéquam, muitas vezes, as suas práticas tendo presente "um modelo de classe média do que constitui a "boa família" e a "educação apropriada".

A escola assume-se como valorizadora de forma de ser e estar que advém das relações de "forças simbólicas entre as classes", o professor, enquanto "representante da cultura legítima", tende a reconhecer e a reforçar aqueles que com ele se identificam. (FORMOSINHO, 1988).

A educação das crianças e jovens é uma preocupação dos pais e também dos educadores, em que o professor possui um papel complexo, desafiador, mas principalmente, mediador e motivador do ensino-aprendizagem (PICANÇO, 2012).Neste sentido, enquanto o profissional em educação se aperfeiçoa em ser dinâmico, comunicativo e inovador nas suas práticas pedagógicas é necessário que, em contrapartida, os pais estabeleçam com eles uma parceria, um esforço contínuo em partilhar objetivos e reconhecer que esse suporte mútuo é para o bem comum dos alunos (PICANÇO, 2012).

No que diz respeito a crianças com NEE, cabe aos professores dar apoio aos pais, auxiliando-os e dando suporte no desempenhar da função de família, de forma que não lhes cobre tanto em relação à execução das tarefas exclusivamente de competência da escola, tendo em vista que não são especialistas (CARDOSO, 2011). 


\subsection{A INTEGRAÇÃO DE CRIANÇAS COM NEE EM CLASSE REGULAR}

Não é tarefa fácil a integração e para isso, é necessário ter em mente que o meio em que a criança com NEE está inserida, faz toda a diferença no seu desenvolvimento. Portanto, ao se falar em alunos com NEE, também se fala das suas interações com o meio ambiente, em que a escola deve proporcionar igualmente à família - um ambiente minimamente restritivo possível (CARDOSO, 2011).

A inclusão não requer apenas que o aluno com NEE seja colocado em uma escola de ensino regular, mas sim, que seja criado um ambiente propício ao seu aprendizado, ao seu desenvolvimento, sendo imprescindível que tenha suas boas condições físicas e humanas garantidas pela família, além de empenho e disponibilidade pelos profissionais em educação, onde oportunidades sejam criadas para que eles possam interagir com outras crianças, dividindo os mesmos espaços e, acima de tudo, Ihes proporcionar os estímulos essenciais ao ensinoaprendizagem, tendo sempre as famílias como parceiras (CARDOSO, 2011).

De acordo, com Saraiva e Wagner (2013), uma explicação hipotética é que uma boa relação entre família e escola, influencia positivamente na integração de crianças com NEE na turma de classe regular. Além disso, estes autores também salientam que a existência de associação de pais e encarregados de educação pode contribuir para uma boa relação família e escola na integração de crianças com NEE (SARAIVA; WAGNER, 2013).

Segundo Paro (2000) a escola percebe que algumas famílias têm mais dificuldade em ajudar no desenvolvimento educativo da criança, por muitas vezes não terem a devida oportunidade de aprendizado, de frequentar uma escola, mas ainda assim a escola precisa dessa continuidade do ensino-aprendizagem, no ambiente familiar (PARO·, 2000). 
Conforme salientam Saraiva e Wagner (2013), as atividades mais solicitadas pela escola aos pais e encarregados de educação são a participação em melhoramento da escola, com a participação em dinheiro, participação na construção e desenvolvimento da avaliação de projetos que a escola desenvolve. Além disto, pode também envolver estratégias de comunicação na relação família e escola como reuniões de pais, contatos telefônicos e notas escritas (SARAIVA; WAGNER, 2013).

Compreende-se, portanto, que incluir alunos com NEE requer uma intervenção educativa que possibilite o seu progresso na escola, o que, dependendo da problemática, implica alterações a nível do currículo, das estratégias e dos recursos, que, por vezes, não são fáceis de concretizar tendo em vista as limitações que podem se apresentar no ambiente escolar ou familiar.

\section{CONSIDERAÇÕES FINAIS}

Com a realização deste estudo foi percebido que os aspectos fundamentais que embasam as questões de dificuldades de aprendizagem de alunos com necessidades especiais na educação, em seus conceitos, trazem a perspectiva de um ensino mais voltado à preparação do sujeito para a vida. Um ensino de qualidade que inclua o cuidado ao educando, em parceria com a família e com a comunidade onde vive, visando à eficácia no processo de evolução das suas aprendizagens, considerando as questões que se remetem a formação de uma escola com a capacidade de incluir os alunos com NEE em seus aspectos físicos, afetivos, sociais e cognitivos.

Vale ressaltar que todo professor, durante o seu percurso como educador, vai encontrar em qualquer momento da sua vida, integrantes da sua turma ou escola, alunos com NEE. É muito provável que seja confrontado com situações para as quais não foi devidamente preparado pedagógica e psicologicamente. Deste modo, o professor vai ter que adotar atitudes e procurar a melhor maneira de dar resposta às necessidades destes alunos. 
Nesta perspectiva, o objeto de estudo refere-se à participação da família, da criança e do adolescente com NEE. Uma relação família e escola numa abordagem multifacetada que se inscreve na vasta área que é a da Educação Especial.

O resultado evidenciou como demanda principal, a participação da família no decorrer dos estudos de seus filhos, visando à redução de uma melhor aprendizagem, a família tendo a participação ativa na escola junto com os professores e colegas de sala garante a continuidade deste e no ambiente familiar faz com que haja uma evolução positiva no desenvolvimento da criança e jovens com NEE.

Neste sentido se o sucesso da criança com o NEE passa pela participação dos pais na escola, então as atitudes e predisposição de pais e professores, face à implantação e manutenção da inter-relação, torna-se pertinente, uma pertinência se relaciona com a inovação ou mudança e com o fato de os pais serem parceiros fundamentais nesse procedimento de mudança.

Do exposto, esse estudo propõe a reflexão, a partir do levantamento bibliográfico, sobre as relações que pais e professores estabelecem entre si e em como isso reflete no rendimento escolar de seus filhos/alunos, além disto, compreender o modo como se constrói essa relação, está presente no sucesso da criança com NEE.

Ao término desta análise, busca-se mostrar que os pais inquiridos acreditam que o trabalho do professor tem contribuído bastante para o desenvolvimento do seu filho com NEE, ou seja, na visão dos pais o papel do professor é fundamental para o crescimento do seu filho. Percebeu-se que os pais têm demonstrado um grande interesse em conhecer a dinâmica de vida dos seus filhos, pela abordagem de assuntos que lhes dão a oportunidade para interagirem e, como tal, pode-se inferir que todos os pais de crianças com NEE podem dar o seu contributo para melhorar o processo da integração e da aprendizagem. 


\section{REFERÊNCIAS}

AINSCOW, M. Understandingthedevelopmentof inclusive schools.London:Falmer Press. 1999.

BALLONE, G. B. Dificuldades de Aprendizagem (ou Escolares). 2004. Disponível em: http://virtualpsy.locaweb.com.br/index.php?art=49\&sec=19. Acesso em: 02 mai. 2021.

BRANDÃO, M. T.; FERREIRA, M.Inclusão de crianças com necessidades educativas especiais na educação infantil. 2013. Disponível em: https://www.scielo.br/j/rbee/a/RdYKyf485LtXLGjN6n5yKtn/?lang=pt. Acesso em: 05 mai. 2021.

BRASIL. Ministério da Educação. Saberes e práticas da inclusão: recomendações para a construção de escolas inclusivas. [2. ed.] / coordenação geral SEESP/MEC. Brasíla : MEC, Secretaria de Educação Especial, 2006. 96 p. (Série : Saberes e práticas da inclusão).

Ministério da Educação. Lei no 9.394, de 20 de dezembro de 1996. Estabelece as Diretrizes e Bases da Educação Nacional. Disponívelem: http://www.planalto.gov.br/ccivil_03/leis/l9394.htm. Acessoem: 20 jun. 2021.

. Ministério da Educação. Secretaria de Educação Especial. Marcos Político-Legais da Educação Especial na Perspectiva da Educação Inclusiva. Brasília, DF, 2010. Disponível em: http://pfdc.pgr.mpf.gov.br/atuacao-e-conteudosde-apoio/publicacoes/educacao/marcos-politico-legais.pdf. Acesso em: 15 mai2021.

CARDOSO, Maria Rosa Cândido António. Inclusão de Alunos com Necessidades Educativas Especiais no Ensino Básico: Perspectivas dos Professores. Instituto Superior de Educação e Ciências: Lisboa, 2011. Disponível em: https://comum.rcaap.pt/bitstream/10400.26/10759/1/Tese_Rosa_Cardoso.pdf. Acesso em: 20 jul. 2021. 
DAVIS, D.; et al. As Escolas e as Famílias em Portugal/Realidade e Perspectivas. Lisboa: Edições Livros Horizonte, 1994.

DÍAZ, Félix. O processo de aprendizagem e seus transtornos. Salvador : EDUFBA, 2011.

ELIAS, L. C. S. Crianças que apresentam baixo rendimento escolar e problemas de comportamento associados: caracterização e intervenção. Tese de Doutorado. Programa de pós-graduação em psicologia. Ribeirão Preto, SP: 2003.

ESTRADA, A. A. Os fundamentos da teoria da complexidade em Edgar Morin. Akrópolis Umuarama, v. 17, n. 2, p. 85-90, abr./jun. 2009.

FERNANDES, A.O saber em jogo. Porto Alegre: Artmed, 2001.

FORMOSINHO, J. O sistema educativo-Conceitos. In Análise social e Organizacional da Educação. Lisboa: E.S. 1988.

GALLO, Alex Eduardo; ALENCAR, Juliana Da silva Araújo. Psicologia do desenvolvimento da criança.Maringá-PR, 2012. Disponível em: http://www.ficms.com.br/web/biblioteca/CESUMAR\%20-

\%20PSICOLOGIA\%20DO\%20 DESENVOLVIMENTO\%20HUMANO.pdf. Acesso em: 16 jun. 2021.

GUERRA, M. A. S. A escola que aprende. Coleção Cadernos do CRIAP, Porto, ASA, 2000.

IOSIF, Ranilce Mascarenhas Guimarães. Qualidade da educação na escola pública e o comprometimento da cidadania global emancipada: implicações para a situação de pobreza e desigualdade no Brasil. Disponível em: https://repositorio.unb.br/bitstream/10482/2560/1/Tese_RanilceMascarenhasGlosif.p df. Acesso em: 22 jun. 2021. 
LEONARDO, Nilza Sanches Tessaro. Inclusão escolar: um estudo acerca da implantação da proposta em escolas de ensino básico. Relato de Pesquisa. Rev.

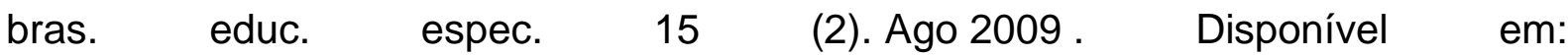
https://www.scielo.br/j/rbee/a/Cfd6gDNpb5wM8zxwmNXwC QS/?lang=PT. Acesso em: 15 jun. 2021.

LOUREIRO, Maria Alice Gonçalves Azevedo. Os Alunos com Dificuldade Intelectual e Desenvolvimental Ligeira e a Educação para os Valores - Que perspetivas?. Felgueiras, 2013

MARQUES, RA Escola e os Pais, como Colaborar? Lisboa: Texto Editora. 1999.

MAZER, S. M.;et al. Dificuldades de Aprendizagem: revisão de literatura sobre os fatores de risco associados. Psic. da Ed., São Paulo, 28, 1ํsem. de 2009, pp. 7-21. Disponível em: http://pepsic.bvsalud.org/pdf/psie/n28/v28a02.pdf. Acesso em: 15 mai. 2021.

MIRANDA, A. A. B. História, Deficiência e Educação Especial. Reflexões desenvolvidas na tese de doutorado: A Prática do Professor de Alunos com Deficiência Mental, UNIMEP, 2003. Disponível em: http://livrosdamara.pbworks.com/f/historiadeficiencia.pdf. Acesso em: 19 mai. 2021.

MORATO, P. Mais ética, menos estética. Contributo para uma cultura da inclusão. Revista de Educação Especial e Reabilitação, v.10, n.1, p.7-11, 2003.

MORIN, E. Os sete saberes necessários à Educação do futuro. São Paulo: Cortez, 2011.

OLIVEIRA,Suélen Cristiane Marcos de. O processo de adaptação das crianças na educação infantil: os desafios das famílias e dos educadores da infância. Presidente Prudente, 2018.

PARO, Vitor Henrique. Qualidade do ensino: a contribuição dos pais. São Paulo: Xamã, 2000. 126p. 
PERRENOUD, Phillipe. Dez novas competências para uma nova profissão.Universidade de Genebra, Suíça 2001 In Pátio. Revista pedagogica (Porto Alegre, Brasil), $\mathrm{n}^{\circ} 17$, Maio-Julho, pp. 8-12.

PICANÇO, Ana Luisa Bibe. A relação entre escola e família - as suas implicações no processo de ensino aprendizagem. Lisboa, 2012. Disponível em: https://comum.rcaap.pt/bitstream/10400.26/2264/1/AnaPicanco.pdf. Acesso em: 20 jul. 2021.

SARAIVA, Lisiane Alvim;WAGNER, Adriana. A Relação Família-Escola sob a ótica de Professores e Pais de crianças que frequentam o Ensino Fundamental.Ensaio: aval. pol. públ. Educ., Rio de Janeiro, v.21, n. 81, p. 739-772, out./dez. 2013.

Disponível

em: https://www.scielo.br/j/ensaio/a/mQHVP55HKZghCGcrrqv9qzC/?lang=pt\&format=pdf . Acesso em: 20 jul. 2021.

VYGOTSKY, L. S. A construção do pensamento e da linguagem. São Paulo: Martins Fontes, 2000.

Enviado: Agosto, 2021.

Aprovado: Setembro, 2021. 